\title{
jip \\ Long-Distance Nationalism: A New Road to Refugees' Identity Formation in When the Moon is Low and Hinterland
}

\author{
Nosheen Akhtar \\ Independent Scholar \\ nosheen_akh@hotmail.com
}

\begin{abstract}
My article discusses long-distance nationalism which provides numerous Afghan refugees with the chance to bridge the territorial gap between their home and host countries with an aim to develop a re-configured national identity. Working through Nadia Hashmi's novel When the Moon is Low and Caroline Brothers' Hinterland, I problematise the national identity of the Afghan refugees. Refugees are people who have left their homeland in the hope of finding protection; however, not only are they marginalised but are also pigeon-holed through the creation of a stereotypical identity of a 'refugee' that is bound within national boundaries. This promotes their subjugation and intensifies a re-configured long-distance nationalism in the refugee characters in the novels. Incorporating Roger Zetter's concept of labeling, Ellen Lammers' theorisation of categorisation and the concept of long-distance nationalism as presented by Nina Glick Schiller and George Eugene Fouron, I theorise how longdistance nationalism forges a trans-border citizenship among the Afghan refugees as a reaction to their reductive categorisation. In doing so, my article serves as one way of addressing the complexities of the Afghan refugee crisis.
\end{abstract}

Keywords: Long-distance nationalism, Afghan refugees, trans-border citizenship, refugee identity 
The recent worldwide refugee crisis has generated a new debate regarding social segregation and categorisation of forcibly displaced people as they continuously face the non-integrative policies of various host nations. Every year, millions of people from developing countries leave their homeland to flee from its political and economic troubles but end up stranded at sea or on the borders of other countries (Kadletz). Those who somehow cross the borders of these countries and get access to the host nations are first stripped of their individual identities and are then allocated the stereotypical identity of a 'refugee' by the host nations. This creates in the refugees a sense of displacement and places them in a situation of statelessness. In addition, they are further labelled and segregated on the basis of their national affiliations which forces the refugees to recall their past and to re-seek an emotional and psychological connection with the countries of their birth. Therefore, my article problematises the idea of the national identity of the Afghan refugees living in various European nations such as Greece, England and France depicted in Nadia Hashmi's When the Moon is Low and Caroline Brothers' Hinterland. In order to highlight the emergence of a reconfigured national identity of the Afghan refugees, I have integrated Roger Zetter's concept of labeling, Ellen Lammers' concept of categorisation, and the concept of long-distance nationalism presented by Nina Glick Schiller and George Eugene Fouron.

Being a Pakistani, I have witnessed the influx of Afghan refugees in Pakistan over the last three decades as a consequence of, first and foremost, the Soviet war in Afghanistan in the late 1970's, and then, the US led war against terrorism in 2001. Since this issue is so close to home, I have analysed the treatment that the Afghan refugees have received in European countries such as Greece, France and England, in order to highlight how this treatment has contributed in the making of a re-configured national identity as is shown in When the Moon is Low and Hinterland. Despite their different nationalities, the writers of both novels have highlighted crucial problems faced by Afghan refugees such as their ill treatment at the hands of host countries, their stereotyping on the basis of their nationality, nostalgia, and a strong affiliation with the home country. These texts serve as the perfect site for viewing and analysing the global refugee crisis because the depiction of characters aims to foreground a newly created national identity of the Afghan refugees which is not the same as the one the refugees were born with, rather the new national identity is a more intensified version of the earlier national identity that has been displaced. This emergent national identity is practiced in the form of long-distance nationalism which does not necessitate the physical presence of the Afghan refugees in their own homeland and provides them with 
an opportunity to develop a trans-border citizenship which only requires them to be emotionally linked with the country of their birth.

When the Moon is Low covers the story of a mother and a son called Fereiba and Saleem. Fereiba, a school teacher, lives in Kabul with her husband and children but her life implodes when the Taliban rise to power and her family becomes the target of the new regime. After the murder of her husband, Ferieba is forced to flee Afghanistan and seek refuge with her sister's family in London. Traveling with forged papers, Ferieba crosses the border of Iran with her three children and starts a journey which reduces her status from a respected wife and loving mother to that of a helpless refugee.

Similarly, Hinterland is based on the story of two brothers, eight-yearold Aryan and fourteen-year-old Kabir, who are forced to flee Afghanistan after the death of their parents. Motivated with the hope of survival, security, and education, both brothers reach Iran by hiding in different trucks. Throughout their journey, the older brother teaches Aryan the map they will follow to reach London: Kabul - Tehran - Istanbul - Athens - Rome - Paris - London. In their struggle to reach London, they are exposed to violence, hunger, cold, rape, and exploitation. To contextualise these texts, the next section outlines the conditions that forced the Afghan refugees to develop a reconfigured national identity as a consequence of their travails.

\section{Long-distance Nationalism, Trans-border Citizenship, and Afghan Refugees: A Theoretical Overview}

The refugee crisis has become a major point of discussion not only on social and print media but also in literature. Writers and scholars belonging to different nations have raised their voices to highlight the injustices being done to refugees and their state of existence in different host nations. What makes my stance different from other scholars' is my attempt to present a non-western perspective regarding the enforcement of a stereotypical national identity on Afghan refugees and its evolution into long-distance nationalism.

I primarily utilise Roger Zetter's concept of labeling whereby an individual identity is replaced by a stereotypical identity with a categorical prescription of needs. Zetter has discussed the process of labeling in the context of African refugees in his article "Labeling Refugees: Forming and Transforming a Bureaucratic Identity" and has explained in detail how African refugees living in Cyprus are stereotyped in public policy practices using certain bureaucratic tools including stereotyping, conformity, designation, identity disaggregation, 
and political/power relations. I extend and deploy this concept in the context of the portrayal of Afghan refugees in Hashmi's When the Moon is Low and Brothers' Hinterland as they are stamped with the stereotypical identity of a 'refugee' once they cross the borders of their own homeland. Carrying with it the connotations of helplessness, dependency, and misery, this enforced identity turns individuals who have names and distinctive identities into figure of pathos. They are no longer taken as people possessing talents or skills, but as dependent people who have specific needs and requirements. One such requirement is the provision of refuge in the form of refugee camps in the host countries where refugees live in conditions that are not conducive to their respectable survival.

My article also takes on board Ellen Lammers' notion of categorisation. For Lammers, categorisation is an artificial process that involves turning people such as refugees into one-dimensional characters that accounts for their dehumanisation by the society at large. The refugees are sub-categorised on the basis of their nationalities and are labeled as 'Syrian refugees', 'Afghan refugees', 'African refugees', etc. This categorisation enables the host nations to create in the refugees an internal sense of hatred towards each other. Furthermore, perceiving each other through the lens of difference, refugees do not allow refugees belonging to other nations to enter their refugee camps. Thus refugees also perpetuate discrimination among themselves through the process of categorisation.

My research deploys the concept of long-distance nationalism which involves practicing one's nationalism at a distance from the country of one's birth. Presented by Nina Glick Schiller and George Eugene Fouron, this idea strengthens my discussion of trans-border citizenship which allows forcibly displaced people to own and practice their nationality from distance. The concept of long-distance nationalism has previously been employed in studies pertaining to Haitian migrants and their nationalism in the United States of America, however, my research utilizes this concept vis-à-vis the development of a strong national identity in Afghan refugees which has not been extensively explored before. The characters depicted in the selected texts have shown the emergence of longdistance nationalism which is a more intensified version of the earlier form of nationalism that was displaced. This new nationalism enables the depicted Afghan refugees to develop as well as practice trans-border citizenship in a place where they were looked down upon because of their affiliation with the country of their birth. In this way, my article serves as an attempt to examine the Afghan refugee identity within the scenario of trans-border citizenship and long-distance nationalism. 


\section{Identity Enforcement: The Beginning of a New Journey}

We live in a world which is plagued by the phenomenon of forced displacement as people belonging to various conflict ridden states such as Afghanistan, Syria, and Palestine are forced to flee their countries and seek refuge in the so-called safe and protected societies of first world nations such as the USA, Britain, France, and many others. However, they have to face constant rejection by many Western nations. Highlighting this xenophobic response of the European nations, U.S NEWS quoted a Gallup study in its articled titled "World Less Accepting of Migrants, Study Finds" that "citizens in many countries are becoming less tolerant of migrants, led by European nations on the frontlines of the recent years of refugees and asylum-seeker inflows". This illustrative picture of the unwelcoming response received by refugees in the host states has also been painted by Hashmi and Brothers where the host European nations have stripped the Afghan people of their individual identities and allocated to them the stereotypical identity of a 'refugee' which has contributed a lot in exacerbating their plight. They are accepted in the new nations not as individuals with distinct personalities but only "as refugees" (Hashmi 127).

The term 'refugee' is widely used in the study of the phenomenon of forced displacement but no one can deny the fact that it is also one of the most misunderstood terms in the world as it is label associated with weakness, dependence, helplessness and victimhood (Al-Saadi 1). Behind this label, there exists a world of individuals with names, stories, personalities, traits and talents which are ignored in the host countries. Characters such as Ferieba, Saleem and Samira in When the Moon is Low along with Kabir and Aryan in Hinterland are all carrying with them the stories of their survival and suffering along with the loss of their loved ones. However, in the host states, they are deemed to be nobody, that is, people without any individual identity living a temporary life, torn between nations because the label of a refugee assigned to them is based on a delinking process whereby an individual identity is replaced by a stereotyped identity (Zetter 44). These characters want to be viewed and treated according to their individual personalities and talents but they are reduced to becoming meaningless, useless, nameless and faceless people, mere "shadows that disappeared in the sun" (Hashmi 190). They can be considered as living ghosts who, despite living in the European countries, "did not exist" for the European citizens (Hashmi 190). This had happened because the label of a 'refugee' had led to their artificial construction as a one-dimensional homogeneous category of people thereby erasing their individualities (Lammers 22). 
No matter what names they have, the talents they possess, or the services they might offer, this one-dimensional category of people is judged and treated according to pre-decided as well as forcibly-allocated images which, despite being stereotypical in nature, are accepted and recognised universally. One such image is that of a helpless and miserable person. This image is not only confirmed but also strengthened through the clichéd presentation of a refugee's clothing, for instance, by showing them as wearing dirty, frayed and damaged clothes. Hashmi has depicted the Afghan refugees as being very "much like their clothing - tired, frayed versions of their former selves" (187). This frayed clothing of the Afghan refugees has become their identity marker and has contributed a lot in making them a distinct social category which is doomed to be exiled. Consequently, the Afghan refugees in When the Moon is Low are not only driven out but are also forced to live far from the city of Athens, in Attiki Square, where their existence is stamped with an identity mark in the form of their threadbare clothing.

This visual manifestation of identity has even enabled Saleem, who is new in Greece and is unaware of the refugee situation in the country of Greece, to spot other Afghan refugees "from a distance" (Hashmi 187). This shows that clothing acts as one of the most important variables in imposing categorisation upon the Afghan refugees. It creates distinctions, which, in the words of Emma Haddad, is the main reason in making the problem of refugees a complicated one (1). The clothing of the Afghan refugees has also contributed significantly in making them figures of pathos embodying uselessness and meaninglessness. Frayed clothing has done nothing more than portray the Afghan refugees "as helpless victims of external forces" (Lammers 29). This portrayal of the Afghan refugees as victims is quite visible in the extract quoted below:

There were men and boys everywhere, milling about outside makeshift tents or sitting on overturned pails. There were two small fires burning, with people sitting or lying around them, drinking palmfuls of water from five-gallon buckets. The squalor rivaled that of Kabul's worst-hit areas. This was the dark side of Athens, the secret world of people who did not exist. (Hashmi 189-190)

This extract shows that the Afghan refugees need to be thankful for the fact that they have been accepted and provided accommodation. No matter what sort of abject situation they have been thrown into by the government of Greece, they must be "passive, silent, apolitical, grateful and dependent" (Besteman 59).

However, the story does not end here as the Afghan refugees are further compartmentalised on the basis of their nationality. This makes their situation ironic as they are first stripped of their national identity by being allocated the label of 'refugees' and then re-categorised under the same national label to single 
them out among other refugees as is shown in the extract below:

"Who are you", the African asks ...

"We just got here", Aryan says. "We are looking for a place to spend the night"

"Where are you from then?

"Afghanistan ..."

"Well, you are in the wrong place. This isn't the jungle you know" (Brothers 81; emphasis added).

The word 'jungle' that I have emphasized here has a negative connotation. It refers to a place associated with remoteness and danger. Earlier, it was the continent of Africa which had been called a 'jungle' by western writers but now it is Afghanistan that stands for the darkness and illnesses that prevail in jungles. A jungle is, "where the Afghans sleep. It is in the dunes. There are only thorn bushes, though, there are not really any trees" (Brothers 81). This shows the biased and racist attitude of the Africans who have absorbed and internalised the stereotypes regarding refugees of other ethnicities. The Africans had also been colonised and 'othered' but now the times have changed and and African refugees indulge in the discriminatory practices of othering and categorisation to which they had been subjected earlier. This is evident in Hinterland as it is not a EuroAmerican but an African character who informs the reader that the African camp is called "Little Africa' whereas the Afghan camp is the "jungle full of thorns and bushes" (Brother 81). These thorns and bushes stand for the dangers that the Afghan people bring with themselves to the peaceful life of the European people. Although the Afghan refugees are given permission to live in European societies but their presence is limited as they are only allowed to live in the refugee camps and are not allowed to go outside. If they do so, then they are caught and treated inhumanly by the police. The police does send them back but only after "taking their frustration out on the refugees" which include "grabbing people by the arm and shoving them into a van waiting at the port. Thighs overlapping, shoulders pressed together ... refugees who had been languishing in a Greek detainment cell for days, weeks, months" (Hashmi 234-235). Although international law has given a proper definition of the term 'refugee' and has charted out laws identifying and securing their rights, but "on the streets, those laws offered as much protection as a broken umbrella in a hurricane" (Hashmi 217). Thus, the Afghan refugees are given the least consideration when it comes to justice as there is no law which can hold the culprit responsible for the downfall and exploitation of the Afghan refugees. The categorisation of the Afghan people and the treatment they received because of this categorisation was the main reason that forced them to become nostalgic about their past, a phenomenon that 
will be expanded upon in the next section.

\section{The Afghan Refugees' Need to Remember their Past}

In a world where the forcibly displaced Afghan people are left unaccepted, the past is something which gives them a chance to escape from the present injustices and provides them with a sense of belonging. The world, they discovered after their forced migration, has given them nothing and has taken from them their hope of survival and their dream of securing a prosperous future. It has made them regret their decision of leaving their homeland and coming to a place where they are neither welcomed nor required. It has also made them realise that the life in their own homeland was still better than the hopeless one they chose to have in alien nations. Hashmi's portrayal of Ferieba's character shows this regret over coming to Europe and leaving behind a life which was better than the present one. Although she has decided to move on but somewhere and somehow she misses the life she had had in the past in her own homeland. She is unable to accept the change and suffering this migration has brought in the life of her children, "I wanted my children to be children. I wanted my children to laugh, to play... to learn. I wanted them to do the things that I should have done as a girl. How far must we go? How far must we run?" (Hashmi 170). This quote represents the feelings of almost all the Afghan refugees who left their homeland and their loved ones just because they wanted to have a future for their children, which unfortunately was never provided. That is why Ferieba suffers when she looks at her children, especially Saleem who wanted to have a school life and stops everytime he sees a school:

But that was a different time, a different Saleem. This Saleem longed for a school with classmates, with friends. He longed for a normal life. More painful than Kabul, the normal life was now touch-ably close and yet unreachable. The longing brought him here, to the shaded, grassy field of the schoolyard. He passed the school every day on his way to the truck shop. It was a constant reminder of how things could be different. (Hashmi 154)

This extract shows the denial of basic human rights to refugees. Although many first world countries claim to provide every possible facility to the refugees but there are many things which will never be provided to them such as education given in schools which are meant primarily for European children. Saleem, being a refugee from a failed state, can only long to get education in a European school because this dream will never turn into a reality.

Such circumstances have done nothing other than making the Afghan refugees regret their decision of coming to Europe and have made them turn towards their past where they had respect, security, and identity. The character 
of Ajmal in When the Moon is Low expressed feelings of regret in the following manner, "If I had known how things were here, I don't know if I would have left Afghanistan. Maybe it would be better to die on our own soil than to be chased out of everywhere we go like stray dogs" (Hashmi 376). Not only Ajmal, but Saleem also holds the same feelings of regret. The narrator reports, "[b]ut he was tired - fatigued as if his veins carried lead instead of blood. He was tired of having nothing to eat and tired of worrying about money. He was tired of watching over his shoulder. Leaving Kabul may have been a great mistake after all. Things might have gotten better (Hashmi 339).

Leaving Kabul has suddenly become the biggest mistake the Afghan refugees have ever made and that is why they want to go back which is evident from their wish to be buried in the soil of their own homeland. Ferieba, time and again, mentions gray-haired Afghans who would always say, "bury me in Afghanistan when I die. Return me to the land I came from" (Hashmi 221). To be buried in one's homeland shows the strong connection these Afghan refugees have developed with their ancestral land. For them, Afghanistan is still a better place to live in as compared to the European world. This hints at the emergence of a renewed strong national identity that contrasts with an earlier sense of identity in which they had seen Afghanistan merely as, "a land of widows, widowers, orphans and the missing" (Hashmi 221); but now, after their sufferings, Afghanistan has become a better place to live in.

This sudden shift in perspective reflects the change this forced migration has brought about in the personalities of the Afghan refugees as they develop a deeper attachment to their homeland. Although the Afghan refugees cannot physically go back to their country because of its unstable political situation, but their stronger emotional tilt towards their nation can be witnessed in their shared feelings of remorse. That is why they started accepting their roots by practicing and promoting their national identity in the alien nations of Europe. Aryan in Hinterland is quite confident when it comes to revealing his national identity and he was not scared at all when an Italian officer asked him where he belonged. Instead of panicking, he replied in the following manner:

'Where is your passport?' he [the Italian officer] says.

'No passport,' says Aryan ...

'Where are you from?'

'Afghanistan.'

... 'You know to come to Europe you need a passport and a visa', the policeman says. 'You have to go home to your country and get them'. (Brothers 62)

Aryan knew well that his words could result in his deportation, still he chose not 
only to reveal but also to promote his national identity. Aryan's act shows that the territorial gap does not and cannot stop the Afghan refugees from affiliating themselves with their nationality. They have created a trans-border citizenship which only demands from them to be emotionally connected with their country of birth.

That is why despite knowing the fact that they would have to face more difficulties, the Afghan refugees bridged the territorial gap and connected themselves with their country and its people on the emotional level. This was because they had faced difficult, "conditions... in the new land”, which encouraged their, "belief and practices that contribute to long distance nationalism" (Schiller and Fouron 22). It was the hostile behavior of the European nations which forced the Afghan refugees to believe that they would never be allowed to become nationals of the host nations. Consequently, they accepted the bitter fact that the idea of transnationalism and open borders is vague and empty. This ultimately paved the way towards long-distance nationalism which made the Afghan refugees own, accept, and promote the same national identity on the basis of which they were stereotyped and marginalised by the European states.

Before their forced migration, the Afghan refugees had never had much of a reason to understand the importance of their nationality because they lived in Afghanistan and were identified as 'Afghans', which they took for granted. Just like a small drop of water that brings hope in a drought, the national identity of the Afghan refugees appeared as their only option of relief amidst constant rejection and extreme exploitation. It made them realise the fact that no matter where they went, their circumstances would not change. In When the Moon is Low, Ajmal expresses his feeling of dissatisfaction with migration in the following words, "[b]ut we are not in much better shape. Look at us. How long do you think we can live here? People are getting sick. The town wants the jungle gone. Even the Red Cross workers say trouble is coming soon" (Hashmi 376). This dissatisfaction with their new life played a vital role in enabling them to bridge the territorial gap and to re-connect themselves with their nation and its people. These are important characteristics of long-distance nationalism, which will be elaborated in the next section.

\section{The Newly Emerging Long-Distance Nationalism}

Long-distance nationalism allows the Afghan refugees to embrace their nationality and to practice their national identity while living in the alien host nations as it only demands from them to be emotionally affiliated with the country of their 
birth. Distance or geographic location, in this context, stands only in terms of self-constructed lines that could be changed or erased at anytime one wishes. What matters is the realisation and affiliation of one's subjectivity and sentiments with a certain existing nation or state. However, bridging a territorial gap and building a connection with the past requires a medium that would enable forcibly displaced people to end their individual differences and feel associated with each other in the host countries. In the context of the Afghan refugees, this medium is provided in the form of their attempts to share with each other the stories of their past which enabled them to ignore artificially-constructed territorial lines and connect with their national identity.

One of the most important characteristics of long-distance nationalism is the assertion of, "common identification with an ancestral territory" (Schiller and Fouron 20), that can emerge and happen among people living in places located at different geographic locations as they start focusing on, "ideas about common descent and shared radicalised identities" (Schiller and Fouron 20). In the context of the Afghan refugees, remembering the past and sharing with each other the stories of childhood, of festivals, and of individual identities have helped them to realise that they are somehow connected to each other because of their common descent. Their past has provided them with a chance to understand, organise and recognise their identity in relation to their nationality. Aryan, in Hinterland, explains the importance of recalling their past and sharing stories with each other in the following manner:

Digging back through the past, clutching at stories that seem to ossify into something more lifeless with each retelling, is becoming more exhausting each time. Yet without the retelling, some vital thread will be broken; it is as if in reminding Kabir of their past he is also reminding himself, and in that way, each becomes the keeper of the other's identity. (Brothers 32)

Although the events of the past have become meaningless for the Afghan refugees but they never lost their importance as it is the repetition of these stories which has not only helped the Afghan refugees to stay connected with their national identity but also enabled them to protect it at any cost.

The Afghan refugees share with each other the stories of their struggle, the journey of their sufferings and the pain caused by the loss of their loved ones. This brings them even closer and connects them through their shared and common experience of hardships. It is as if sharing with each other the story of their difficult life becomes a medicine which heals their wounds and unites them under the umbrella of nationalism. Through the character of Saleem, Hashmi has tried to tell the reader that every Afghan refugee living in the host nation 
has experienced extreme pain and has lost loved ones which has brought about psychological problems in the Afghan refugees. Being unaware of the agony of other refugees, Saleem yelled at Ali for being too obsessed with the rain. Later, he comes to know that Ali's obsession with the rain is the result of the incident of his parents' death, "[h]e was outside when his mother called... She told them it looked like it was going to rain and they should get back inside. His brother listened, Ali did not... he wishes he had gone back into the house and been crushed by those rockets instead of living with the memory of watching them die" (Hashmi 308). Right after getting to know about Ali, Saleem not only, "burned with remorse", but also kept, "his mouth shut" (Hashmi 308). It was not only because he was ashamed of his behavior but also because, for the first time, he realised that he was not alone in his suffering because not a single Afghan refugee had a happy story to tell. They were all together and united not only because they belonged to the same country but also because they had experienced the same problems and had been affected by them. The realisation of their being connected to each other had led them to own and promote nationalism even if they were living far away from their country because distance could not stop them from going back to their past and affiliate themselves with their nationality.

There is no doubt that the national identity of the Afghan refugees was displaced because they wanted to have a safe refuge in Europe. However, the journey from being an 'Afghan' to an 'Afghan refugee' made them realise that they were living in a world which firmly believes in differences among people because they belong to different states which can never be equal in any respect. This realisation made the Afghan refugees in the selected novels understand and promote the existence of a separate land which provides them with a sense of self-respect and a feeling of belonging. According to Schiller and Fouron, an important characteristic of long-distance nationalism is that it requires the promotion of "'the image of the world as divided into separate, sovereign territorial based states", but the, "relationship between citizens and state", goes beyond the physical existence of territorial lands (21). This is true in the context of the Afghan refugees as they have somehow rejected the conventional idea of nationalism and have started embracing and practicing their nationality while trying to live and adjust in the European societies. They are emotionally bound with their homeland which shows that they have created a form of trans-border citizenship which requires them to relate with their homeland. That is why the Afghan refugees started stating clearly that they belonged to Afghanistan. Brothers, through the dialogue between Aryan and Kabir in Hinterland, has shown 
that it is enough for one to have national affiliation even if one has forgotten about his or her homeland:
'Am I an Afghan?'
'What do you mean, are you an Afghan?'
'Can you still be an Afghan if you can't remember anything about it?'
'Of course, you are an Afghan. I am an Afghan, you are an Afghan. Our family is from Afghanistan'.
'But if someone asks. I can't tell them what it's like. I can remember more about Iran and Istanbul and this farm than Afghanistan'. (30)

This extract shows that Kabir does not only himself believe in his affiliation with a separate territorial state but is also trying to make his little brother understand the importance of one's homeland. Although Aryan has forgotten about his country, but still he is known to be an Afghan and nothing can change this fact. That is why Kabir replies to Aryan's question in the following manner, "Of course, you are an Afghan. Do you think you would be here if you were an Egyptian or an American or an Eskimo?" (Brothers 30). Kabir has accepted the fact that the world is treating them badly because they belong to the war ravaged state of Afghanistan and it is because of their roots that they have become refugees. This made them feel further connected to their country regardless of whether they remembered it or not. Even the blurred image and the lost memory of Afghanistan in their minds served as their bridge between their past identity and their present standing in the world.

The Afghan refugees in the novels under analysis were now ready to accept and promote their national identity. They were mentally prepared to tell the world that they belonged to a country which suffered. That is why in Hinterland, Aryan reminded Kabir time and again of the importance of accepting one's national identity and this constant reminder eventually made Kabir accept and promote it. Even after the unfortunate death of Aryan, which occurred because of the cold temperature of the container meant to carry carcasses of animals, Kabir never forgot about it, "he reminded me about the puppies and the canary that couldn't fly or sing and the pigeons on the rooftop in Afghanistan. He asked me if I'd chosen a birthday month and told me never to forget I was an Afghan, even if I did not remember much about it" (Brothers 125). It is this long-distance nationalism which has allowed the Afghan refugees to take specific actions which shows that they can do anything to tell the world that even though they belong to a state which has faced downfall, nevertheless, their relationship with their nation is still intact. In the words of Schiller and Fouron, long-distance nationalists, "may vote, demonstrate, contribute money, create work of art; give birth and fight, kill and die for a homeland" (20). Afghan refugees, living in the European countries, 
have also emerged as long-distance nationalists in the sense that they openly demonstrate their affiliation with their home country. They are completely ignoring the fact that this demonstration could result in further suffering which may be in the form of beatings, arrests or deportation. The portrayal of Saleem's character in When the Moon is Low illustrates this change as earlier he had tried to hide his identity from the Greek police which captured him and sent him back to Turkey but, at the end, the acceptance of his national identity enabled him to tell a stranger about himself, his family, and country. When an old man asked him about his identity, he replied immediately and without hesitation, "[M]y name is Saleem Waziri. My family lived in Kabul” (Hashmi 363).

Thus, this journey from being forcibly displaced people who preferred to hide their national identity to refugees who are eager to tell the world their names, identities and of their homeland, is symbolic of the fact that it is the cold and unwelcoming response from the European countries which has made the Afghan refugees to go back to their past and strongly hold onto their national identity. It is not the same identity which they had had in their homeland, but a more intensified version of it as they are carrying it with themselves more openly in a place where people believe in divisions and look down upon the refugees from war torn states. Without worrying about the consequences, the novels show that the Afghan refugees have clearly and openly started promoting their national identity through the phenomenon of long-distance nationalism which has provided them with a chance to ignore the territorial gap and to feel connected with their homeland. This emergent national identity is there to stay no matter how much the Afghan refugees must suffer because this identity does not need them to be physically present in their territorial state. Rather, they have developed a form of trans-border citizenship which requires them only to be sincere with their homeland.

However, to be sincere with one's homeland does not imply or encourage hatred towards the host nation. It means to relate to one's own people, culture and society as they help in developing a social connection that is necessary for a person to survive in this world. We have stepped into an era where the phenomenon of long-distance nationalism is providing millions of forcibly displaced people with an opportunity to not be ashamed of their national identity and present it proudly without being affected by the stereotypes and labels associated with it. This is evident in many Afghan refugees living in various European nations who have not only accepted their roots but have also embraced their nationality. However, they do not carry any harsh feelings towards their host countries and that is why 
the main characters in When the Moon is Low and Hinterland want to continue their journey no matter how much suffering it will bring. Despite knowing the fact that Europe is not happy on the arrival of refugees and is treating them badly, Saleem does not hate the host countries and continues with his journey towards England which symbolises the fact that he has managed to conduct his thoughts as well as his actions in a logical and objective way. This is one of the reasons why he does not react emotionally towards the protest held by the French people in the support of refugees and makes a logical decision of entering the train tunnels which lead towards England:

A crowd of young French protesters gathered in front of the camps. Some chanted. Some waved their fists in the air...

"Their own people shouting for us!"

But Saleem saw more when he looked at the mass. They must know something. Maybe they had gotten word about that something. Saleem watched as more activists began to join the group, two or three at a time.

"Ajmal, this is not good. We should get out of here"

"Now? When we have just found hundreds of friends? I bet things will get better. We just have to wait and see". (Hashmi 377)

This extract shows that unlike Ajmal, Saleem critically reflects on the situation and comes up with a reasonable solution to the problem, that is, leaving France. Saleem has realised that this protest is held either because some order has been issued by the French government to raze the Afghan refugee camp or to harm the Afghan refugees in any way possible. That is why the French people have gathered there to stop the approaching mishap, which the Afghan refugees are not aware of, and in which he does not want to be caught up. This protest created a sense of deja vu because back in Afghanistan his family could not take a timely decision before the rise of the Taliban, which resulted in the death of his father at their hands. He does not want the Afghan refugees to repeat the same mistake because, "if they don't plan for tomorrow, there won't be one" (Hashmi 377). This shows that Saleem has somehow stepped out of the passive enclosure which was enforced upon him by the host nations through stereotyping and so he decides to seize the moment before things get worse.

What needs to be added here is the fact that it is this long-distance nationalism which has enabled Saleem to become a responsible as well as an active member of his community of Afghan refugees. Instead of becoming sad over the difficulties brought about by his forced migration or hating the host countries for making his life miserable, Saleem has developed the habit of thinking logically, analysing the circumstances, and of making connections between the events of the past and the present. It is this comparison which has made him take on an 
active role and decide what is best for him and his friends, "I don't want to see. We will be caught in the middle of whatever this is. Just like in Afghanistan" (Hashmi 377). Saleem does not want to wait because he knows that this protest will create more problems for the Afghan refugees. Instead of wasting his life in a never-ending wait for good days, Saleem wants to leave for England because he has accepted the fact that his circumstances are never going to change and it is he who must decide for himself. Long-distance nationalism has transformed Saleem, a boy who was passive and silent at the start of his refugee life, into a man who takes logical decisions not only for himself but also for his people.

The absence of hatred towards the host nations and the existence of logical as well as active participation on the part of Afghan refugees in the novels is symbolic of the fact that the forcibly-imposed idea of nationalism which demanded from nationalists to hate other countries has not only been negated but has also been abandoned by them. The conventional idea of nationalism has not only been created but also promulgated universally by the privileged class of people with the purpose of fulfilling their own political and economic interests. However, the universal acceptance of this artificially-constructed nationalism has been challenged by the phenomenon of long-distance nationalism which, on the one hand, allows refugees to hold on strongly to their national identity, and, on the other hand, provides them with an opportunity to look at the future with an active, logical, and reasonable approach. Instead of breeding extremists whose nationalism could become a reason for terrorism, long-distance nationalism is providing the world with moderate, stable, critical and balanced individuals who are not driven by their emotions and are able to contemplate over and mediate through specific situations.

Long-distance nationalism has not only made the Afghan refugees embrace their national identity but has also provided them with a space where they could detach themselves from their emotional affiliations, make comparisons, think logically, and come up with sound solutions. This has, in turn, helped the Afghan refugees to break the shell of passivity and take on an active social and political role in their societies which is motivated by their strong ties with their nationality, that is, their trans-border citizenship. This trans-border citizenship, as practiced in long-distance nationalism, can be considered as one way of advancing, "projects of epistemic and subjective decolonisation and in building communal futures" (Mignolo xxviii). I argue that trans-border citizenship could serve not only as a way towards subjective decolonisation but also as a medium to solve the worldwide refugee crisis and bring a solution to the sufferings of millions 
of forcibly displaced people belonging to conflict ridden states like Afghanistan. Instead of moving in the endless circle of acceptance and non-acceptance, of citizenship and alienation, the host countries could consider the possibility of allowing refugees to develop, accept, and practice their trans-border citizenship. This will provide both the host nations and refugees with an opportunity to come closer, ignore their differences, and invent possible ways of living in accordance with one another.

Thus, the exploration of long-distance nationalism through the selected novels brought to light the loose presence of artificially-constructed territorial lines which can be ignored and erased. It also made the Afghan refugees realise the fact that it is not their physical presence in their homeland which matters, but their emotional link and affiliation with their country that plays a major role in making them internalise their national identity. It is this emotional affiliation which made them adopt their trans-border citizenship that not only allowed them to embrace their national identity but also to present it confidently. The analysis of the selected texts revealed that the Afghan refugees managed to develop trans-border citizenship using the medium of telling each other stories of their past which helped them to forget their individual differences and come closer. The examination of the differences brought in by forced migration in the personalities of the Afghan refugees highlighted the fact that instead of breeding extremists, whose nationalism could become a reason for their terrorism, longdistance nationalism is providing the world with moderate, stable and reasonable individuals. It thus provides both the refugees and the host nations one way of moving on and of ignoring differences to have a communal future. We need to have a policy of accommodation that ought to be followed by First World countries so that they can support refugees on humanitarian grounds. There is a need to understand it as a moral responsibility which will help the world in sorting out this problem and come up with sound solutions.

\section{The Way Forward}

Long-distance nationalism has opened the doors to a new sphere where both the host countries and refugees can understand each other and make logical decisions regarding adjusting with one another. We all know that the worldwide refugee crisis is here to stay for a long time, and if this is the case, then why not take into consideration the option of allowing refugees to embrace their trans-border citizenship as it allows both the host nations and refugees to live harmoniously. On the one hand, it allows refugees to have an emotional link with the country 
of their birth, while, on the other hand, it gives the host nations the option of allowing the refugees to live on their lands and to mingle with their nationals. What is required is a policy of accommodation that would enable the host countries to accept refugees and provide them with equal political and economic opportunities. Instead of looking at refugees through the lens of difference, the world needs to approach them as individuals having talents and skills which could be utilised for the betterment of the host societies. Instead of seeing them as a burden, why not perceive them as a moral responsibility and come up with a sound solution to the crisis? For this, the world must treat refugees as human beings instead of perceiving them as a threat or a burden. Furthermore, it also needs to consider the option of trans-border citizenship which provides a space where refugees and the host nations live together amicably. 


\section{Works Cited}

Al-Saadi, Yazan. "How Refugee Became a Bad Word and How to Reclaim It." OpenCanada.org, 28 Oct. 2015, https://www.opencanada.org/features/ unhcr- legacy-how- refugee-became-bad-word-and-how-reclaim-it/. Accessed 22 Nov. 2017.

Brothers, Caroline. Hinterland. Bloomsbury, 2012.

Ciacek, B. Domonika. "Palestine as 'a State of Mind': Second-Generation Polish and British Palestinians' Search for Home and Belonging." Journal of Ethnic and Migration Studies, vol. 44, no. 11, 2017, pp. 1915-1931, https: / / doi.org/10.1080/1369183X.2017.1369868. Accessed 2 Aug. 2018

Haddad, Emma. "Who is (not) a Refugee?" CADMUS EUI Research Repository, 2004, https: / / cadmus.eui.eu/bitstream/id/1769/sps2004-06.pdf/. Accessed 9 Nov. 2017.

Hashmi, Nadia. When the Moon is Low. Harper Collins Publishers, 2015.

Kadletz, Bruna. "Displaced, Dispossessed and Disposable." News Deeply, 26 July 2016, HYPERLINK "http: / / www.newsdeeply.com/refugees/com munity/2016/07/26/displaced-dispossessed-and-disposable" www.newsdeeply.com/refugees/community/2016/07/26/displaceddispossessed-and-disposable. Accessed 29 Sep. 2021.

Lammers, Ellen. Refugees, Gender and Human Security: A Theoretical Introduction and Annotated Bibliography. International Books, 1999.

Mignolo, D. Walter. Local Histories/Global Design: Coloniality, Subaltern Knowledge and Border Thinking. Princeton UP, 2000.

Schiller, Nina and Georges Eugene Fouron. Georges Woke up Laughing: Long Distance Nationalism and the Search for Home. Duke UP, 2001.

"World Less Accepting of Migrants, Study Finds." U.S. NEWS, 23 Sep. 2020, https: / / www.usnews.com/news/best-countries/articles/2020-09-23/ countries-less-accepting-of-migrants-study-finds. Accessed 27 Sep. 2021.

Zetter, Roger. "Labeling Refugees; Forming and Transforming a Bureaucratic Identity." Journal of Refugee Studies, vol. 4, no. 1, 1991, pp. 39-62, https: // doi.org/10.1093/jrs/4.1.39. Accessed 6 July 2017. 